\title{
Variação sazonal na actividade física e nas práticas de lazer de adolescentes portugueses
}

\author{
M. Paula Santos \\ Helena Gomes \\ José C. Ribeiro \\ Jorge Mota
}

https://doi.org/10.5628/rpcd.05.02.192

\section{RESUMO}

A compreensão dos factores que condicionam e influenciam a actividade física dos jovens é particularmente relevante, pois permite a identificação dos atributos pessoais, dos sistemas sociais e do envolvimento que estão associados aos comportamentos activos. O objectivo do presente trabalho foi o de verificar a variação sazonal na actividade física e nas práticas de lazer dos adolescentes. A amostra foi constituída por 444 adolescentes de ambos os sexos, com idades compreendidas entre os 12 e os 18 anos. A actividade física e as actividades de lazer dos alunos foram avaliadas duas vezes durante o mesmo ano lectivo, em períodos sazonais distintos, através de um questionário (Telama et al.; Cloes et al.). Os principais resultados revelam que as raparigas são mais activas durante a primavera/verão do que durante o período de outono/inverno. As actividades organizadas ou de competição mais frequentemente referidas são o "futebol" entre os rapazes e a "ginástica" entre as raparigas. Apenas os mais novos referem maior participação nestas actividades durante o período de primavera/verão. Entre as actividades não organizadas "andar de bicicleta" é a mais escolhida por rapazes e raparigas ao longo de todo o ano. A segunda actividade não organizada preferida pelos rapazes é "jogar futebol" mas entre as raparigas tais escolhas parecem mais diversificadas, uma vez que "jogar futebol" e "correr" são actividades com alguma popularidade. A participação em actividades não organizadas ocorre com maior frequência, independentemente do sexo, grupo etário ou período sazonal.

Palavras-chave: actividade física, adolescentes, lazer, estações do ano.

\author{
Universidade do Porto \\ Faculdade de Ciências do Desporto \\ e de Educação Física \\ Centro de Investigação em \\ Actividade Física, Saúde e Lazer \\ Portugal
}

\begin{abstract}
Seasonal variations in Portuguese adolescents' physical activity and leisure-time activities

Understanding factors that influence adolescents' physical activity is particularly important because it allows the identification of the personal attributes, social systems and the environment that are related to the active behaviors. The purpose of this study was to examine the seasonal variation in adolescent's physical activity and in leisure-time activities. The sample comprised 444 adolescents of both sexes, aged between 12 and 18 years old. Physical activity and leisure-time activities were assessed by questionnaire (Telama et al.; Cloes et al.) at two different times in the same school year. The main results showed that girls are more active during spring/summer than during fall/winter period. Organized activities that were more frequently reported were "soccer" among boys and "gymnastics" among girls. Youngsters reported greater participation in these activities during spring/summer time. Non-organized physical activities had higher frequencies of participation, independently of sex, age group or the seasonal period.
\end{abstract}

Key Words: adolescents, physical activity, leisure time, seasons. 


\section{INTRODUÇÃO}

Compreender os factores que influenciam os comportamentos dos adolescentes é fundamental para o desenvolvimento de programas de intervenção orientados para a promoção da saúde entre os jovens (3). A adolescência é um período crítico do desenvolvimento no qual se inicia a adopção de alguns comportamentos relacionados com a saúde, como a dieta e a actividade física, que tendem a permanecer durante a vida adulta (4). A actividade física durante a juventude não só exerce uma influência favorável na maturação biológica e aptidão física dos jovens (5) e no seu desenvolvimento pessoal e social, mas também é importante pois é maior a probabilidade de que um jovem activo venha a ser um adulto activo (6).

A actividade física necessária para a obtenção de benefícios para a saúde pode ser livremente escolhida e realizada no tempo de lazer, ou integrada na rotina diária dos adolescentes (7). No entanto, a actividade física, enquanto comportamento relacionado à saúde, é muitas vezes colocada em competição com outros valores, comportamentos e atitudes, que podem ter mais relevo para as aspirações dos jovens (8).

Torna-se então importante compreender de que forma é possível influenciar os comportamentos decisivos na apropriação de um estilo de vida saudável, com inclusão da prática de actividade física. Além disso, parece também importante aumentar a participação de crianças e adolescentes em programas regulares de actividade física que possibilitem vivências positivas durante a juventude, de forma a estabelecer a prática de actividade física como um hábito de vida (9). O problema é que a actividade física não parece ser um comportamento que domine as experiências de vida dos adolescentes. Muitas crianças e adolescentes têm uma visão negativa da actividade física. Entre as possíveis causas desta pobre atracção pela actividade física estão a falta de apoio dos pares e dos familiares, uma fraca percepção de competência e ainda as experiências negativas decorrentes da prática de actividade física, especialmente no contexto escolar (10). Tais razões podem comprometer a prática regular de actividade física e, consequentemente, a manutenção de um estilo de vida activo ao longo da vida (11). Além disso, as deficientes oportunidades para o envolvimento dos jovens em actividades de lazer, nomeadamente de lazer activo, podem também estar relacionadas com a ausência de recursos formais, tais como infraestruturas para a prática desportiva, ou mesmo dificuldades na utilização de recursos informais, como os parques e mesmo a rua, pois os problemas de insegurança, de contacto com as drogas e com a violência são factores que podem limitar fortemente as escolhas por actividades de lazer activo.

Estudos recentes têm evidenciado que a actividade física pode ser influenciada por factores do ambiente $(12,13)$. De acordo com Dishman et al. (14), os factores ambientais que podem influenciar a prática de actividade física podem ser classificados em sociais e físicos. Os factores do ambiente social estão relacionados com a influência da família, amigos ou profissionais de saúde. Entre os aspectos do ambiente físico estão o clima, o acesso a instalações adequadas, bem como a disponibilidade de tempo.

Embora os estudos acerca da influência do ambiente físico na regularidade da prática de actividade física sejam escassos $(15,16)$, alguns autores referem que pequenas alterações no ambiente físico são capazes de influenciar positivamente os indivíduos, no sentido de uma vida mais activa $(17,18)$.

A compreensão da importância dos factores ambientais físicos (e.g., temperatura, estações do ano e proximidade de espaços lúdicos) tem sido considerada como um importante foco de interesse no âmbito da promoção da saúde. Actualmente, os factores ambientais devem ser considerados como potenciais influências no aumento ou restrição à prática da actividade física $(13,19)$. Embora a variação sazonal da actividade física tenha sido ainda pouco estudada, algumas diferenças no número de horas com luz solar, na temperatura e na precipitação, parecem merecer atenção enquanto factores passíveis de condicionar a actividade física. Estudos realizados com adultos referem que a maior parte da actividade física de lazer ocorre nos meses de verão $(20,21)$. A influência da variação sazonal na estabilidade da actividade física dos adolescentes não tem sido suficientemente quantificada. Aparentemente, o conhecimento de tais influências, não apenas no nível de actividade física dos jovens mas também nas escolhas das actividades de lazer, pode servir de apoio à elaboração de programas de intervenção que considerem as características do meio ambiente e das 
condições climáticas e que favoreçam a escolha de actividades e comportamentos relacionados com um estilo de vida activo e saudável.

Foi objectivo deste estudo: (i) Identificar as práticas de lazer dos adolescentes e suas variações de acordo com as estações do ano; (ii) Avaliar a estabilidade sazonal da actividade física de acordo com o sexo dos sujeitos; (iii)Verificar as diferenças nas escolhas por actividades organizadas ou não organizadas nos diferentes períodos sazonais, de acordo com o sexo dos adolescentes.

\section{MATERIAL E MÉTODOS \\ Caracterização da Amostra}

A amostra do presente estudo foi constituída por 444 alunos, de níveis de escolaridade compreendidos entre o $7^{\circ}$ e o $12^{\circ}$ ano, pertencentes a três escolas públicas do Concelho de São Pedro do Sul, na região Centro de Portugal. A idade dos alunos que participaram no estudo está compreendida entre os 12 e os 18 anos, (média de idades de 14.66 anos; $\mathrm{DP}=1.76$ ), sendo 226 do sexo feminino e 218 do sexo masculino, constituindo $50.9 \%$ e $49.1 \%$, respectivamente, do total da amostra. Os grupos de idade foram escolhidos no sentido de representar os diferentes níveis de escolaridade, correspondendo o grupo dos 12 aos 14 anos ao $3^{\circ}$ Ciclo do Ensino Básico e o grupo dos 15 aos 18 anos ao Ensino Secundário. Os critérios de elegibilidade dos sujeitos foram a participação nas aulas de Educação Física, terem reportado a ausência de problemas de saúde, o consentimento dos pais e a concordância do aluno. Foi garantida a participação anónima de todos os sujeitos.

\section{Procedimentos de recolha e análise dos dados}

Os alunos foram avaliados duas vezes durante o mesmo ano lectivo, em períodos sazonais distintos. A primeira avaliação ocorreu durante os meses de Novembro e Dezembro de 2002. A segunda avaliação ocorreu no final de Maio de 2003. Os resultados obtidos na primeira avaliação foram considerados como referentes ao período do Outono/Inverno e os resultados da segunda avaliação foram considerados como referentes ao período da Primavera/Verão. Para a avaliação da actividade física foi utilizado um questionário desenvolvido por Telama et al. (1) cuja aplicação à população portuguesa foi anteriormente descrita $(22,23)$. Resumidamente, o instrumento era composto por 5 questões, que incluíam a frequência da actividade física de lazer, a intensidade desta actividade, participação em actividade física organizada, participação em actividade física não organizada e, ainda, participação em competições desportivas. Todas as questões permitiam apenas respostas numa escala de 1 a 4 . Um índice foi formado a partir do somatório da pontuação obtida em cada uma das respostas do questionário, cujo valor variava entre 5 e 20 . As actividades de lazer foram avaliadas por intermédio de um inventário que apresentava uma lista de 21 actividades onde os jovens assinalavam a respectiva participação ou não participação. Este instrumento, elaborado por Cloes et al (2) foi anteriormente aplicado à população portuguesa $(3,23)$.

\section{Procedimentos estatísticos}

Para a análise estatística dos dados foi utilizado o programa SPSS (Statistical Package for the Social Sciences) para Windows, versão 12.0.

O índice de actividade física elaborado a partir da pontuação dos alunos no questionário de actividade física não apresentava uma distribuição normal. Foi verificada a simetria da distribuição, no sentido de garantir os pressupostos de utilização do teste $t$ para amostras emparelhadas (24), para a comparação do índice de actividade física nas duas avaliações sazonais. A média e o desvio-padrão do índice de actividade física foram calculados para cada sexo e período sazonal.

Foram calculadas as frequências de participação nas actividades de lazer, bem como nas actividades físicas organizadas e não organizadas, de acordo com o sexo e o grupo etário e em cada período sazonal. O teste não paramétrico do Qui-quadrado $\left(\chi^{2}\right)$ foi utilizado para a comparação entre as frequências de participação em actividades organizadas e não organizadas, bem como nos tipos de actividade física praticada em cada período sazonal. O nível de significância foi colocado em 0.05 .

\section{RESULTADOS}

No quadro 1 são apresentados os resultados da comparação entre as avaliações da actividade física realizadas nos dois períodos sazonais distintos. 
Quadro 1. Variação do índice de actividade física ao longo das estações do ano de acordo com o sexo.

\begin{tabular}{lcccc}
\hline & \multicolumn{2}{c}{ Indice de actividade física } & $t$ & $\mathrm{p}$ \\
& Outono/inverno & Primavera/verão & & \\
$\mathrm{X} \pm$ d.p. & $\mathrm{X} \pm$ d.p. & & \\
Raparigas & $10.73 \pm 3.2$ & $11.44 \pm 3.7$ & -4.04 & 0.000 \\
Rapazes & $13.34 \pm 3.5$ & $13.17 \pm 3.4$ & 1.08 & 0.278 \\
\hline
\end{tabular}

Os resultados revelam um aumento significativo no valor médio do índice de actividade física durante o verão, mas apenas entre as raparigas da amostra. Entre os rapazes, não foram observadas alterações estatisticamente significativas no índice de actividade física da primeira avaliação, no outono/inverno, para a segunda avaliação, na primavera/verão. A seguir apresentam-se as frequências de participação em actividades de lazer da totalidade da amostra, de acordo com a estação do ano.
Quadro 2. Participação nas práticas de lazer de acordo com as estações do ano.

\begin{tabular}{|c|c|c|c|c|}
\hline & \multicolumn{2}{|c|}{ Inverno } & \multicolumn{2}{|c|}{ Verão } \\
\hline & $\mathrm{n}$ & $\%$ & $\mathrm{n}$ & $\%$ \\
\hline 1. Ouvir música & 420 & 94.6 & 427 & 96.2 \\
\hline 2. Tocar música ou cantar & 99 & 22.3 & 104 & 23.4 \\
\hline 3. Ver televisão ou vídeo & 426 & 95.9 & 411 & 92.6 \\
\hline $\begin{array}{l}\text { 4. Trabalhar para ganhar algum } \\
\text { dinheiro }\end{array}$ & 94 & 21.2 & 135 & 30.4 \\
\hline $\begin{array}{l}\text { 5. Conversar com os } \\
\text { amigos(as) }\end{array}$ & 398 & 89.6 & 406 & 91.4 \\
\hline $\begin{array}{l}\text { 6. Namorar, estar com } \\
\text { namorado[a] }\end{array}$ & 113 & 25.5 & 125 & 28.2 \\
\hline $\begin{array}{l}\text { 7. Jogar às cartas, jogos de } \\
\text { vídeo ou computador }\end{array}$ & 338 & 76.1 & 336 & 75.7 \\
\hline $\begin{array}{l}\text { 8. Ler (livros, revistas, banda } \\
\text { desenhada) }\end{array}$ & 288 & 64.9 & 291 & 65.5 \\
\hline $\begin{array}{l}\text { 9. Praticar desporto } \\
\text { orientado/competição }\end{array}$ & 176 & 39.6 & 184 & 41.4 \\
\hline $\begin{array}{l}\text { 10. Assistir a acontecimentos } \\
\text { desportivos }\end{array}$ & 249 & 56.1 & 269 & 60.6 \\
\hline 11. Fazer trabalhos da escola & 344 & 77.5 & 298 & 67.1 \\
\hline 12. Ir à festas/discoteca & 97 & 21.8 & 133 & 30.0 \\
\hline $\begin{array}{l}\text { 13. Participar em actividades } \\
\text { de "Arte e Expressão" }\end{array}$ & 33 & 7.4 & 37 & 8.3 \\
\hline 14. Estar só (relaxar, pensar] & 303 & 68.2 & 332 & 74.8 \\
\hline $\begin{array}{l}\text { 15. Fazer compras ou ver } \\
\text { montras }\end{array}$ & 188 & 42.3 & 211 & 47.5 \\
\hline $\begin{array}{l}\text { 16. Ir ao cinema, concerto ou } \\
\text { teatro }\end{array}$ & 189 & 42.6 & 234 & 52.7 \\
\hline $\begin{array}{l}\text { 17. Realizar trabalho de } \\
\text { solidariedade social }\end{array}$ & 29 & 6.5 & 34 & 7.7 \\
\hline $\begin{array}{l}\text { 18. Ajudar nos trabalhos } \\
\text { domésticos }\end{array}$ & 337 & 75.9 & 341 & 76.8 \\
\hline $\begin{array}{l}\text { 19. Participar em } \\
\text { assoc./movimentos de } \\
\text { juventude }\end{array}$ & 180 & 40.5 & 159 & 35.8 \\
\hline $\begin{array}{l}\text { 20. Visitar parentes ou } \\
\text { pessoas conhecidas }\end{array}$ & 261 & 58.8 & 237 & 61.5 \\
\hline $\begin{array}{l}\text { 21. Praticar desporto não } \\
\text { orientado }\end{array}$ & 284 & 64.0 & 328 & 73.9 \\
\hline
\end{tabular}

Entre as práticas de lazer mais referidas pelos jovens estão: "ouvir música", "ver televisão", "conversar com os amigos", "jogar às cartas, jogos de vídeo e computador" e "ajudar nos trabalhos domésticos". Estas actividades são realizadas com maior frequência, tanto no período de outono/inverno como durante o período primavera/verão. De um modo geral, os jovens referem participar mais em activida- 
des de lazer durante a primavera/verão, porém, "ver televisão", "jogar às cartas, jogos de vídeo e computador" e "fazer trabalhos da escola" são actividades em que a maior participação acontece durante o outono/inverno.

De salientar que as actividades mais escolhidas durante os dois períodos sazonais podem ser consideradas como práticas sedentárias. Relativamente à actividade física, verifica-se que "praticar um desporto não orientado" ocupa apenas o $9^{\circ}$ lugar das escolhas dos adolescentes durante o outono/inverno mas a participação neste tipo de actividade aumenta durante a primavera/verão, sendo a $6^{\mathrm{a}}$ actividade mais referida, com $73.9 \%$ de participação. Já a participação em "desporto orientado ou de competição" é apenas referida por $39.6 \%$ dos jovens durante o outono/inverno, mas durante a primavera/verão esta participação também aumenta para $41.4 \%$.

A seguir são apresentadas as frequências de participação em actividade física de lazer dos adolescentes da amostra, em função do sexo e do grupo etário, nos dois períodos sazonais observados.

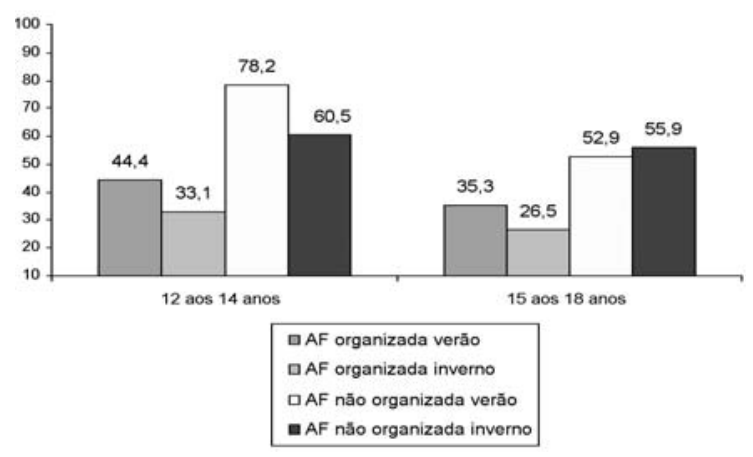

Figura 1. Frequência de participação das raparigas em actividade física nos dois períodos sazonais.

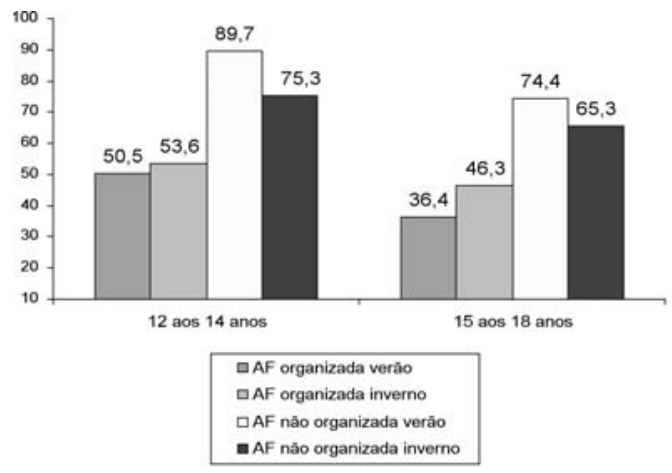

Figura 2. Frequência de participação dos rapazes em actividade física nos dois períodos sazonais.
Verifica-se que os rapazes apresentam frequências de participação em actividade física de lazer superiores às raparigas, nos dois grupos etários e nos períodos sazonais avaliados, seja esta actividade física de natureza organizada ou não organizada. Observa-se ainda que, em ambos os sexos, o grupo dos mais novos é o que refere maior participação em actividade física, tanto no período do inverno como no verão. No entanto, apenas foram encontradas diferenças com resultados significativos durante o verão e nas actividades não organizadas $(\mathrm{p}<0.01)$. De salientar, a maior participação dos adolescentes em actividades não organizadas ao longo do ano e, também, a participação das raparigas em actividades não organizadas, que apresenta uma frequência superior durante o inverno, ao contrário do que ocorre com os rapazes.

Os quadros 3 e 4 apresentam os tipos de actividade física mais referidos pelos jovens, tanto de natureza organizada como não organizada, nos dois períodos sazonais distintos.

Quadro 3. Actividades mais escolhidas pelas raparigas.

\begin{tabular}{|c|c|c|c|c|}
\hline \multirow{4}{*}{$\begin{array}{l}\text { Raparigas } \\
(n=226)\end{array}$} & \multicolumn{2}{|c|}{ Primavera/Nerão } & \multicolumn{2}{|c|}{ Outono/Inverno } \\
\hline & 12 aos & 15 aos & 12 aos & 15 aos \\
\hline & 14 anos & 18 anos & 14 anos & 18 anos \\
\hline & $\%$ & $\%$ & $\%$ & $\%$ \\
\hline \multicolumn{5}{|l|}{ Organizados } \\
\hline Futebol & 8.1 & 5.9 & 4.8 & 3.9 \\
\hline Ginástica & 21.8 & 9.8 & 19.4 & 11.8 \\
\hline Natação & 6.5 & 3.9 & 7.3 & 3.9 \\
\hline Andebol & 2.4 & 6.9 & 0 & 2.9 \\
\hline Atletismo & 5.6 & 2.0 & 0.8 & 0 \\
\hline Outros & 0.8 & 6.9 & 0.8 & 3.9 \\
\hline & \multicolumn{2}{|c|}{$\begin{array}{c}X^{2}=17.07 ; g .1=6 ; \\
p<0.01\end{array}$} & \multicolumn{2}{|c|}{$X^{2}=10.48 ;$ g.l. $=6 ;$ n.s. } \\
\hline \multicolumn{5}{|l|}{ Não } \\
\hline \multicolumn{5}{|l|}{ organizados } \\
\hline \multicolumn{4}{|l|}{ bicicleta } & 20.6 \\
\hline Correr & 14.5 & 14.7 & 10.5 & 8.8 \\
\hline Nadar & 7.3 & 4.9 & 4.0 & 4.9 \\
\hline Jogar futebol & $13 . ?$ & 6.9 & 14.5 & $15 . ?$ \\
\hline Outros & 4.8 & 8.8 & 6.5 & 5.9 \\
\hline & \multicolumn{2}{|c|}{$\begin{aligned} X^{2} & =23.07 \\
\text { g.I. } & =5 ; p<0.01\end{aligned}$} & \multicolumn{2}{|c|}{$X^{2}=1.38 ;$ g.l. $=5 ;$ n.s. } \\
\hline
\end{tabular}


Quadro 4. Actividades mais escolhidas pelos rapazes.

\begin{tabular}{|c|c|c|c|c|}
\hline \multirow{4}{*}{$\begin{array}{l}\text { Rapazes } \\
{[n=218]}\end{array}$} & \multicolumn{2}{|c|}{ Primavera/Verão } & \multicolumn{2}{|c|}{ Outono/Inverno } \\
\hline & 12 aos & 15 aos & 12 aos & 15 aos \\
\hline & 14 anos & 18 anos & 14 anos & 18 anos \\
\hline & $\%$ & $\%$ & $\%$ & $\%$ \\
\hline \multicolumn{5}{|l|}{ Organizados } \\
\hline Futebol & 40.2 & 25.6 & 43.3 & 33.1 \\
\hline Ginástica & 2.1 & 0 & 1.0 & 0 \\
\hline Natação & 1.0 & 0 & 4.1 & 0.8 \\
\hline Andebol & 2.1 & 4.1 & 1.0 & 5.0 \\
\hline Atletismo & 2.1 & 0.8 & 0 & 3.3 \\
\hline Hóquei patins & 1.0 & 3.3 & 1.0 & 2.5 \\
\hline Outros & 2.1 & 1.7 & & \\
\hline & \multicolumn{2}{|c|}{$X^{2}=11.97 ;$ g.I. =?;n.s. } & \multicolumn{2}{|c|}{$X^{2}=12.76 ;$ g.I. $=$ ?; n.s } \\
\hline \multicolumn{5}{|l|}{ Não } \\
\hline \multicolumn{5}{|l|}{ organizados } \\
\hline Andar de & 44.3 & 25.6 & 40.2 & 31.4 \\
\hline \multicolumn{5}{|l|}{ bicicleta } \\
\hline Correr & 0 & 4.1 & 5.2 & 2.5 \\
\hline Nadar & 3.1 & 0.8 & 2.1 & 0 \\
\hline Jogar futebol & 38.1 & 33.9 & 23.7 & 26.4 \\
\hline \multirow[t]{2}{*}{ Outros } & 4.1 & 9.9 & 4.1 & 5.0 \\
\hline & \multicolumn{2}{|c|}{$\begin{array}{c}x^{2}=20.51 \\
\text { g.l. }=5 ; p<0.01\end{array}$} & \multicolumn{2}{|c|}{$X^{2}=7.27 ;$ g.l. $=5 ;$ n.s. } \\
\hline
\end{tabular}

As actividades organizadas ou de competição com maior popularidade são o "futebol", entre os rapazes, e a "ginástica", entre as raparigas. É interessante notar que, durante o período de verão, apenas os grupos mais novos referem maior participação nas actividades referidas (futebol e ginástica).

Observa-se que "andar de bicicleta" é uma actividade não organizada frequente entre rapazes e raparigas, tanto no período de verão como no inverno. As raparigas e os rapazes mais velhos referem esta actividade com mais frequência durante o inverno, enquanto os grupos mais novos o fazem durante o verão. No entanto, apenas durante o verão os resultados apresentam significado estatístico. Entre os rapazes, a segunda actividade não organizada com maior popularidade é "jogar futebol", sendo mais frequente durante o período de verão. Já entre as raparigas observa-se que "correr" e "jogar futebol" são actividades com alguma popularidade, sendo de salientar que a participação entre as raparigas mais velhas na actividade "correr" é mais frequente durante o verão, e na actividade "jogar futebol" no inverno.

\section{DISCUSSÃO}

O tempo livre tem sido assumido como potencialmente importante do ponto de vista da promoção da saúde e da qualidade de vida dos jovens, devido ao seu carácter voluntário e autónomo (3). Embora os efeitos do lazer activo sejam largamente assumidos como benéficos, as escolhas relativas à ocupação do tempo livre entre os jovens nem sempre representam uma elevada participação em actividade física de lazer (8). O presente estudo procurou identificar a participação em actividades de lazer dos adolescentes, bem como as diferenças no nível da actividade física e na escolha por actividades de natureza organizada e não organizada, de acordo com as estações do ano.

Os resultados mostram que as estações do ano podem influenciar o nível de actividade física, bem como as escolhas das actividades de lazer entre os adolescentes. No entanto, apenas as raparigas pertencentes à amostra do presente estudo são significativamente mais activas durante os meses de primavera/verão. Tais resultados sugerem a importância de intervir, no sentido de favorecer a prática de actividade física das raparigas, através de programas de actividade física organizada e de acesso aos locais de lazer, principalmente durante os meses de outono/inverno. As ofertas de actividade física para rapazes e raparigas devem ser diversificadas e, além disso, devem ser realizadas em locais que disponham de condições adequadas do ponto de vista do conforto e da segurança. A influência das estações do ano na actividade física dos jovens também deve ser considerada sob o ponto de vista da própria avaliação dos padrões de actividade física. De facto, estudos referem que a avaliação sazonal da participação em actividade física pode ser mais precisa, pois reduz a probabilidade de os jovens sobrestimarem a sua participação em actividades que só ocorrem durante curtos períodos ao longo do ano (25).

O tempo de lazer tem ocupado um papel cada vez mais importante entre os jovens. As actividades de lazer como ouvir música, estar com os amigos e navegar na internet constituem, actualmente, uma vertente fundamental da vida e também de aprendizagem para os adolescentes (6).

De um modo geral, os resultados do presente estudo são semelhantes aos de outros estudos internacionais, que referem uma participação dos jovens em 
actividades predominantemente sedentárias durante o seu tempo livre $(2,6)$. Num estudo realizado em cinco países europeus com a utilização do mesmo questionário do presente estudo, Cloes et al. (2) verificaram que as actividades mais frequentes eram "ouvir música" com 78.8\%, "ver televisão ou vídeo" com $77.2 \%$, "conversar com os amigos" com $72.1 \%$ e "ler" com $66.8 \%$ das escolhas dos jovens nos países estudados. Também no estudo de Telama et al. (6) as actividades mais referidas pelos jovens dos seis países europeus estudados são "ouvir música", "ver televisão ou vídeo", "ler" e "conversar com os amigos". No entanto, existem diferenças importantes na frequência de participação nas actividades, quando são consideradas as amostras de cada país separadamente, representando não apenas diferenças de oportunidades, mas também diferenças culturais na valorização das actividades (6). Existem limitações na comparação entre as actividade de lazer preferidas por adolescentes de diferentes países, não apenas pelas diferentes formas de compreender as actividades, mas também pelo significado ou importância que cada actividade pode ter para os jovens de um país em particular (2).

A distinção sazonal na ocupação dos tempos livres dos adolescentes portugueses foi descrita anteriormente. No estudo de Matos et al. (3), que utilizou um inventário de actividades de lazer semelhante ao utilizado no presente estudo, os adolescentes também referem maior participação em actividades de lazer durante a primavera/verão, e as actividades mais referidas, independentemente da estação do ano, são também actividades sedentárias. No presente estudo, apenas algumas actividades aparecem com maior frequência durante o período do outono/inverno ("ver televisão ou vídeo", "jogar cartas, jogos de vídeo ou computador" e "fazer os trabalhos da escola"). A maior proporção de jovens a escolher estas actividades durante os períodos mais frios do ano pode estar relacionada com a ausência de oportunidades de lazer mais diversificado, provocada pelas condições do clima e pela precipitação, mas também pode ser influenciada pelas diferentes solicitações no domínio académico. É de salientar que a avaliação referente ao período do outono/inverno coincidiu com o final do primeiro período escolar, enquanto a avaliação referente à primavera/verão foi realizada em meados do terceiro período, ou seja, quase no final do ano lectivo. Isto pode representar uma exigência completamente diferente em termos de trabalho escolar, justificando assim a elevada percentagem (77.5\%) de adolescentes a dedicar o seu tempo de lazer à realização de trabalhos para a escola durante o outono/inverno. Também no estudo de Matos et al. (3) "fazer os trabalhos da escola" foi uma actividade escolhida por $69.5 \%$ dos adolescentes no período do outono/inverno.

A actividade física não é das actividades preferidas para ocupação do tempo livre dos jovens que participaram no presente estudo. No entanto, "praticar um desporto não orientado" é uma actividade escolhida por cerca de $74 \%$ dos jovens durante o período da primavera/verão. Diferentes frequências de participação em actividade física, seja ela organizada ou não organizada, de acordo com a estação do ano são também referidas no estudo de Matos et al. (3), onde se destaca a participação de $66.5 \%$ dos jovens em desporto não orientado durante a primavera/verão e de apenas $39.8 \%$ durante o outono/inverno. Já a participação em actividade física organizada ou de competição é escolhida por $60.5 \%$ e por $35 \%$ dos jovens na primavera/verão e no outono/inverno, respectivamente (3). Tais resultados são semelhantes aos encontrados na amostra do presente estudo, onde a participação em actividade física é mais elevada durante o período da primavera/verão, o que parece indicar que não existem oportunidades suficientes de prática de actividade física durante os meses de outono/inverno. A carência de tais oportunidades pode estar relacionada com a inexistência de instalações desportivas adequadas, com o elevado custo financeiro dos programas de actividade física organizada ou mesmo com a fraca acessibilidade aos espaços de lazer disponíveis. Esta situação parece muito importante entre as raparigas, cujo nível de actividade física, avaliado através do questionário, é significativamente menor durante os meses de outono/inverno. O facto de existirem ainda tantas escolas no nosso país que não possuem instalações desportivas cobertas, onde as próprias aulas de Educação Física são condicionadas pela chuva, pode estar também associado às fracas oportunidades de prática de actividade física entre os jovens. Mesmo fora do contexto curricular, o espaço da escola pode 
ser fundamental, não apenas pela possibilidade de favorecer a realização de actividades não organizadas durante os recreios, mas também para o desenvolvimento de programas de actividade física organizada. No estudo de Telama et al. (6) a participação em actividade física organizada é maior entre os rapazes, porém esta diferença fica diluída na actividade física não organizada. Nos países em que a participação em desporto organizado foi mais elevada (Alemanha e Bélgica), a percentagem de participação em actividades não organizadas foi mais reduzida, ao contrário dos países em que a participação em actividades organizadas foi menor, como na Estónia ou na Finlândia, em que a participação nas actividades não organizadas foi mais elevada, o que pode reflectir diferentes experiências culturais em actividades de natureza distinta.

No presente estudo, a actividade física não organizada é aquela que apresenta frequências de participação mais elevadas, independentemente do sexo, do grupo etário ou da estação do ano. Num estudo realizado por Mota et al. (23), as actividades não organizadas são também as preferidas, excepto entre as raparigas mais activas, que escolhem mais actividades de natureza organizada.

Quando são considerados os dois grupos etários distintos, a participação de rapazes e de raparigas mais novos é mais frequente em actividade física de natureza organizada e não organizada. No entanto, apenas a actividade não organizada realizada no período da primavera/verão apresenta uma frequência significativamente superior. A participação mais elevada em actividade física não organizada sublinha a importância deste tipo de actividade na criação de hábitos de lazer activo entre os adolescentes. O tipo de actividades escolhidas pelos jovens também parece ser importante do ponto de vista da manutenção de hábitos de actividade física ao longo da vida (26). Os resultados do presente estudo apontam para uma preferência generalizada por actividades não organizadas. Entre os rapazes, as actividades preferidas são "andar de bicicleta" e "jogar futebol", nos dois grupos etários e ao longo de todo o ano. Já as raparigas parecem revelar maior diversidade nas preferências de actividades não organizadas, uma vez que, além das actividades mais referidas pelos rapazes, também escolhem "correr" como actividade física não organizada. Tais resultados sugerem algumas implicações na promoção da actividade física entre os jovens, bem como na organização dos currículos de Educação Física. De facto, tem sido sugerido que as actividades competitivas e de equipa tendem a perder popularidade durante a adolescência, enquanto as actividades não organizadas que podem ser realizadas individualmente ou a pares, tendem a ser mais escolhidas pelos adolescentes (27). As raparigas parecem poder beneficiar ainda mais, do ponto de vista da criação de hábitos de actividade física, se forem sujeitas a uma grande variedade de estímulos, ou seja, se tiverem a oportunidade de experimentar diferentes actividades e de aprender habilidades diversificadas. Alguns estudos revelam que a diminuição dos níveis de actividade física entre adolescentes parece estar mais relacionada com a diminuição no número de actividades em que os jovens participam, do que com o decréscimo no tempo despendido em cada actividade (4).

Outros estudos reforçam a noção de que uma participação em desporto escolar pode influenciar a adesão dos jovens a um estilo de vida activo (28). Mais uma vez, podemos referir o importante papel da escola e perceber que há muito ainda por fazer em termos de ofertas de actividades que possam ir de encontro aos interesses e às necessidades dos adolescentes, sendo este aspecto fundamental para que se proporcionem vivências agradáveis e atractivas, que possam ser mantidas ao longo da vida.

\section{CONCLUSÕES}

Os resultados do presente estudo revelam que as raparigas da amostra são mais activas durante os meses de primavera/verão, do que durante o período de outono /inverno.

Os adolescentes referem maior frequência de participação em actividades de lazer durante a primavera/verão. No entanto, algumas actividades como "ver televisão", "jogar às cartas, jogos de vídeo e computador" e "fazer os trabalhos da escola" são actividades em que a maior participação ocorre no outono/inverno.

A actividade física não é das actividades preferidas para a ocupação dos tempos livres dos adolescentes da amostra do presente estudo. Porém, a actividade física não organizada é aquela que apresenta frequên- 
cias de participação mais elevadas, independentemente do grupo etário, do sexo ou do período sazonal.

Entre as actividades organizadas ou de competição mais frequentemente referidas encontram-se o "futebol", entre os rapazes, e a "ginástica", entre as raparigas. Apenas os mais novos referem maior participação nestas actividades durante o período de primavera/verão. Entre as actividades não organizadas "andar de bicicleta" é a mais escolhida, por rapazes e raparigas, ao longo de todo o ano. A segunda actividade não organizada preferida pelos rapazes é "jogar futebol", mas, entre as raparigas, tais escolhas parecem mais diversificadas, uma vez que "jogar futebol" e "correr" são actividades com alguma popularidade entre as raparigas que participaram no estudo.

\section{CORRESPONDÊNCIA}

Maria Paula Santos

Centro de Investigação em Actividade Física, Saúde e Lazer

Faculdade de Ciências do Desporto

e de Educação Física

Universidade do Porto

Rua Dr. Plácido Costa, 91

4200 - 450 Porto

Portugal

msantos@fcdef.up.pt 


\section{REFERÊNCIAS}

1. Telama R, Yang X, Laakso L, Viikari J (1997). Physical activity in childhood and adolescence as predictor of physical activity in young adulthood. Am.J.Prev.Med. 13: 317-323

2. Cloes M, Ledent M, Didier P, Diniz J, Piéron M (1997). Pratique et Importance des Principales Activités de Loisirs chez des Jeunes de 12 à 15 Ans Dans Cinq Pays Européens. ADEPS 159/160: 51-60

3. Matos M, Equipa do Projecto Aventura Social e Saúde. (2003). A saúde dos adolescentes portugueses (quatro anos depois). Lisboa: Edições FMH

4. Aaron DJ, Storti KL, Robertson RJ, Kriska AM, LaPorte RE (2002). Longitudinal study of the number and choice of leisure time physical activities from mid to late adolescence: implications for school curricula and community recreation programs. Arch.Pediatr.Adolesc.Med. 156: 1075-1080

5. Malina RM (1994). Physical activity and training: effects on stature and the adolescent growth spurt. Med Sci.Sports Exerc. 26: 759-766

6. Telama R, Naul R, Nupponen N, Rychtecky A, Vuolle P. (2002). Physical fitness, sporting lifestyles and olympic ideals: cross cultural studies on youth sport in Europe. Schorndorf: Verlag Karl Hofmann

7. Biddle S, Mutrie N. (2001). Psychology of Physical Activity Determinants, well-being and interventions. London: Routledge

8. Mota J. (1997). A Actividade Física no Lazer: Reflexões sobre a sua prática. Lisboa: Livros Horizonte, Lda.

9. Armstrong N, Welsman J. (1997). Young People and Physical Activity. New York: Oxford University Press

10. Sallis J, Owen N. (1999). Physical Activity \& Behavioral Medicine. London: Sage Publications Inc.

11. Sleap M , Warburton P (1992). Physical activity levels of 5-11-year-old children in England as determined by continuous observation. Research Quarterly for Exercise and Sport 63: $238-245$

12. Humpel N, Owen N, Leslie E (2002). Environmental factors associated with adults' participation in physical activity. A review. Am.J.Prev.Med. 22: 188-199

13. Sallis JF, Prochaska JJ, Taylor WC (2000). A review of correlates of physical activity of children and adolescents. Med.Sci.Sports Exerc. 32: 963-975

14. Dishman RK, Sallis JF, Orenstein DR (1985). The Determinants of Physical-Activity and Exercise. Public Health Reports 100: 158-171

15. Sallis JF, Bauman A, Pratt M (1998). Environmental and policy interventions to promote physical activity. Am.J Prev.Med 15: 379-397

16. Sallis JF, Hovell MF, Hofstetter CR, Elder JP, Hackley M, Caspersen CJ, Powell KE (1990). Distance Between Homes and Exercise Facilities Related to Frequency of Exercise Among San-Diego Residents. Public Health Reports 105: 179-185

17. Linenger JM, Chesson CV, Nice DS (1991). Physical fitness gains following simple environmental change. Am.J Prev.Med 7: 298-310

18. Brownell KD, Stunkard AJ, Albaum JM (1980). Evaluation and Modification of Exercise Patterns in the NaturalEnvironment. American Journal of Psychiatry 137: 1540-1545

19. Owen N, Leslie E, Salmon J, Fotheringham MJ (2000). Environmental determinants of physical activity and sedentary behavior. Exerc.Sport Sci.Rev. 28: 153-158

20. Uitenbroek DG (1993). Seasonal variation in leisure time physical activity. Med.Sci.Sports Exerc. 25: 755-760

21. Matthews CE, Freedson PS, Hebert JR, Stanek EJ, III, Merriam PA, Rosal MC, Ebbeling CB, Ockene IS (2001). Seasonal variation in household, occupational, and leisure time physical activity: longitudinal analyses from the seasonal variation of blood cholesterol study. Am.J.Epidemiol. 153: $172-183$

22. Ledent M, Cloes M, Telama R, Almond L, Diniz J, Piéron M (1997). Participation des Jeunes Européens Aux Activités Physique et Sportives. ADEPS 159/160: 61-71

23. Mota J, Esculcas C (2002). Leisure-time physical activity behavior: structured and unstructured choices according to sex, age, and level of physical activity. Int J Behav Med 9: 111-121

24. Twisk JW. (2003). Applied Longitudinal Data Analysis for Epidemiology A Practical Guide. Cambridge: Cambridge University Press

25. Rifas-Shiman SL, Gillman MW, Field AE, Frazier AL, Berkey CS, Tomeo CA, Colditz GA (2001). Comparing physical activity questionnaires for youth: seasonal vs annual format. Am.J.Prev.Med 20: 282-285

26. Tammelin T, Nayha S, Hills AP, Jarvelin MR (2003). Adolescent participation in sports and adult physical activity. Am.J Prev.Med 24: 22-28

27. Bradley CB, McMurray RG, Harrell JS, Deng S (2000). Changes in common activities of 3rd through 10th graders: the CHIC Study. Med.Sci.Sports Exerc. 32: 2071-2078

28. Barnett TA, O'Loughlin J, Paradis G (2002). One- and two-year predictors of decline in physical activity among inner-city schoolchildren. Am.J.Prev.Med 23: 121-128. 